\title{
Attending football matches may be bad for your hearing!
}

Andrew Lau, Chung Shen Chean, Nicholas J Roland, Tristram H Lesser, Samuel C Leong

\section{Introduction}

The UK places limits on workplace noise exposure in order to protect workers from noise-induced hearing loss (NIHL) ${ }^{1}$. The Control of Noise at Work Regulations 2005 mandate that action be taken when workers are exposed to:

- 80-85 dB averaged over an eight-hour working day and/or

- $135-137 \mathrm{~dB}$ at any point ('peak sound pressure')

Noise exposure must not exceed $87 \mathrm{~dB}$ average or $140 \mathrm{~dB}$ peak sound pressure.

For every $3 \mathrm{~dB}$ increase, allowable exposure time is halved. In dose terms, exposure to $90 \mathrm{~dB}$ for four hours is equivalent to the $87 \mathrm{~dB}$ limit (eight hour average).

\section{Objectives}

To undertake a pilot study of noise exposure at Liverpool FC matches, in order to inform the public about any risk to their hearing

\section{Method}

Funding: This study was funded by the British Tinnitus

\section{Association}

Ethical considerations: The study was registered with our institutional review board and formal ethical approval was deemed not to be required

We used the SoundMeter Pro software for Apple iOS (Faber Acoustical, Salt Lake City, UT, USA, v4.3.1) on personal iPhone $7 S^{\prime}$ 's. Recordings were made continuously between the first and final whistles. Data were downloaded and analysed in Microsoft Excel.

\section{$136 \mathrm{~dB}$}

Highest peak sound pressure Liverpool vs Middlesbrough 21 May 2017

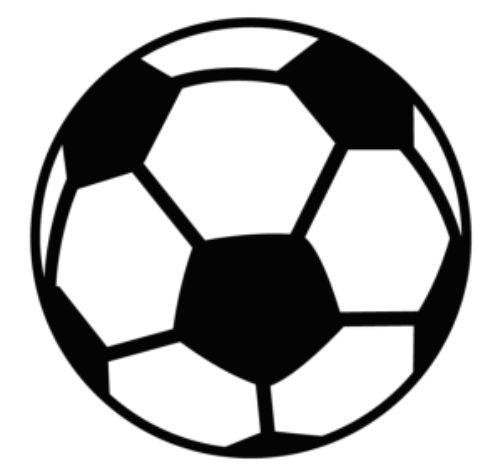

Highest average exposure ( $2 \mathrm{~h}$ ) Liverpool vs Manchester United 14 October 2017

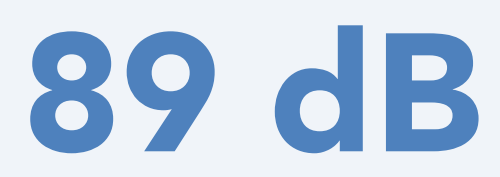

\section{Results}

To date, recordings have been analysed for five matches.

Noise exposure for all matches fell above the action levels detailed above.

For all five matches, mean time weighted noise exposure was $86.97 \mathrm{~dB}$ (range 83.97 to $89.56 \mathrm{~dB}$ ).

Mean peak sound pressure was $132.87 \mathrm{~dB}$ (range 128.43 to 134.58 ) with no match exceeding the workplace limit for a single sound event.

Recordings lasted approximately 2 hours for each match

\begin{tabular}{|c|c|c|}
\hline Match versus & $\begin{array}{c}\text { Noise exposure } \\
\text { (dB) (2h) }\end{array}$ & $\begin{array}{c}\text { Peak sound pressure } \\
\text { (dB) }\end{array}$ \\
\hline Manchester Utd & 89.56 & 131.24 \\
\hline Middlesbrough & 87.75 & 136.61 \\
\hline Sevilla & 87.49 & 134.58 \\
\hline
\end{tabular}

\section{Conclusions}

Even though workplace noise exposure limits do not cover recreational activities, it is recognised that regularly exceeding them can lead to NIHL. With members of staff working at these matches, workplace limits may still be relevant. Our recordings showed that average noise exposure (two hours) approached $90 \mathrm{~dB}$ for some matches, which in dose terms is equivalent to exposure to eight hours at $84 \mathrm{~dB}$, within the action levels mentioned above.

We continue to analyse the recordings from other matches and hope to advise both the public, organisers and funders on this issue.

\section{REFERENCES}

1) Noise at Work. HSE. Available from: http://www.hse.gov.uk/noise/ employers.htm\#noise
Aintree University Hospital W/HS NHS Foundation Trust
( T )

British Tinnitus Association 